\title{
La Conciliación: principales antecedentes y características
}

César Guzmán Barrón

Tomando en cuenta la importancia que tiene para nuestra Universidad, el promover un clima y una cultura de paz, especialmente a través de actividades de capacitación, investigación y divulgación en temas vinculados con la solución de conflictos, es que decide crear su propio Centro de Conciliación, convirtiéndose así en la primera universidad en brindar servicios modernos de conciliación, capacitación y formación de conciliadores.

Nuestro Centro se ha trazado, como uno de sus más importantes objetivos, formar peruanos que a través de la práctica de la Conciliación y otros procesos de solución de conflictos sean protagonistas del desarrollo de nuestro país y de la construcción de una cultura de paz.

$\mathrm{Al}$ asumir nuestro centro, el reto de llevar adelante la Conciliación, nos comprometimos de forma decidida a difundirla, buscando con ello el conocimiento e identificación de la mayoría de peruanos. En este sentido, quisiera a través de este artículo poder transmitir, dentro de un marco general, los antecedentes, principios, características, ventajas y estilos que tiene la Conciliación, y que a continuación desarrollamos.

\section{Conceptos Básicos}

La conciliación es el proceso por el cual dos o más personas en conflicto logran restablecer su relación, gracias a la intermediación de un tercero denominado conciliador.

El conciliador es un facilitador de la comunicación, no ejerce la función de juez, ni de árbitro. Por ello, para los abogados esta tarea 
resulta más difícil que para las demás personas, dado que están acostumbradas a buscar las posiciones de las partes y aplicar la ley, por encima de la razón de las partes.

En su obra Mediación, Folberg y Taylor señala: «la mediación es una alternativa a la violencia o el litigio. Es posible definirla como el proceso mediante el cual los participantes, junto con la asistencia de una persona, aislan sistemáticamente los problemas en disputa con el objeto de encontrar opciones, considerar alternativas y llegar a un acuerdo mutuo que se ajuste a sus necesidades [...] tiene el propósito de resolver desavenencias y reducir el conflicto, así como de proporcionar un foro para la toma de decisiones".

Así mismo Carl A. Slaikeu en su libro Para que la sangre no llegue al río señala que «en su forma más simple, la mediación es un procedimiento a través del cual un tercero ayuda a dos o más partes a encontrar su propia solución a un conflicto. El valor de este procedimiento está en que permite a dos o más adversarios examinar un problema tanto en privado como en reuniones conjuntas, con el objetivo de crear una solución en la que todos ganen, y que responda suficientemente a los intereses individuales (y comunes). Y les permite descartar otras salidas, como juicios o el recurso a la fuerza.

A diferencia de un abogado ante una Corte, el mediador no toma decisiones por las partes, sino que prefiere escuchar, preguntar, sondear, intercambiar ideas en forma negativa y, a veces, provocar, desafiar y confrontar. En este sentido la mediación es una negociación asistida. El mediador es más que un amortiguador entre las partes".

En el Perú, según la Ley № 26872, la conciliación es entendida como una institución por la cual las partes acuden a un centro de conciliación o a los juzgados de paz letrados a fin de que se les asista en la búsqueda de una solución consensual al conflicto. La Ley ha optado por una definición que incide en el rol de colaborador del tercero para lograr una solución voluntaria al conflicto.

\section{Antecedentes de la Conciliación}

En la antigua China la conciliación era el principal recurso para resolver desavenencias. Según Confucio, la resolución óptima de una desavenencia se lograba a través de la persuasión moral y el acuerdo, y no 
bajo coacción. Confucio hablaba de la existencia de una armonía natural en las relaciones humanas, que no debía interrumpirse. La conciliación a gran escala se sigue ejerciendo en la actualidad en la China (Folberg y Taylor, 1992).

Durante siglos la Iglesia ha desempeñado un papel de conciliadora, trátese del párroco, el ministro o el rabí. La Biblia afirma que Jesús es un mediador entre Dios y el hombre, así leemos en Timoteo 2, 5-6 "porque hay un solo Dios, y un solo mediador entre Dios y los hombres». Es más, cuando Pablo se dirige a la comunidad en Corinto les pide que no resuelvan sus desavenencias en el Tribunal sino que nombren a personas de su propia comunidad para conciliar (I Cor. 6, 1-4).

Con la aparición en la Edad Moderna de los nuevos Estados los conciliadores asumen el papel de intermediarios formales.

Desde la década de 1960 la conciliación ha aumentado como un método formal y muy difundido en los diferentes estados de los Estados Unidos y en diferentes campos, no solamente laboral sino también familiar, vecinal, escolar, de propiedad, e incluso en el campo penal. En los últimos años, el uso de la conciliación se ha generalizado en los países de América Latina.

\section{Principios de la Conciliación}

De acuerdo a lo establecido en el artículo segundo de la Ley de Conciliación, Ley No 26872 y en el artículo segundo de su Reglamento aprobado por D.S. No 001-98-JUS, los principios que rigen la conciliación son los siguientes:

\subsection{Equidad}

Concebida como el sentido de la justicia aplicada al caso particular, materia de conciliación.

\subsection{Veracidad}

Búsqueda de lo querido realmente por las partes.

Se refleja en el Acuerdo al que llegan las partes, como la mejor solución.

Lo que interesa no es el acuerdo sino la solución del problema. 


\subsection{Buena fe}

Necesidad de que las partes procedan de manera honesta y leal, conducta que debe llevarse adelante durante todo el procedimiento.

\subsection{Confidencialidad}

Supone, tanto del conciliador como de las partes, guardar absoluta reserva de todo lo actuado.

\subsection{Imparcialidad o neutralidad}

Garantías de seguridad y justicia. Supone la intervención del conciliador durante todo el procedimiento sin identificación alguna con los intereses de las partes.

\subsection{Legalidad}

Expresa conformidad del acuerdo conciliatorio con el ordenamiento jurídico.

\subsection{Celeridad (prontitud)}

Consustancial al procedimiento.

Supone la solución pronta y rápida del conflicto.

\subsection{Economía}

Las partes eliminan el tiempo que les demandaría un proceso judicial.

\section{Características de la Conciliación}

A partir de la idea de conciliación que se ha esbozado anteriormente podemos señalar como principales características las siguientes:

4.1 Conflicto existente.

4.2 La conciliación es fundamentalmente una negociación. Sin negociación no existe conciliación.

4.3 Participación de un tercero. En la conciliación el tercero interviene dando especial importancia en recuperar la relación entre las partes, 
para ello utiliza sus cualidades con el fin de logra que las partes consigan una solución propia. El tercero no es juez ni árbitro.

4.4 Aceptación. Las partes deciden libremente acudir a este proceso; sin embargo, en la Ley de Conciliación éste será un requisito obligatorio desde el 14 de enero del año 2001. Lo que las partes aceptan será al tercero neutral.

4.5 El procedimiento flexible e informal. Los procesos de conciliación no suponen etapas obligatorias ni instancias. Las pruebas no requieren de las formalidades propias del proceso judicial, dado que no existe un juez que les tenga que dar mérito. La participación activa de las partes hace de la conciliación un proceso informal y práctico, donde se llegará a un acuerdo según la voluntad de las mismas.

4.6 Llegar a un acuerdo no es obligatorio. Aun cuando las partes acudan por ley a una conciliación, no están obligadas a llegar a un acuerdo.

4.7 El proceso es coordinado por el conciliador. El llegar a un acuerdo supone el resultado del papel facilitador, del conciliador y de la decisión de las partes.

\section{Ventajas}

\subsection{Comunicación entre las partes}

El conflicto puede ser sano, pero no resuelto es un peligro. En la medida en que la conciliación constituye una alternativa para solucionar conflictos crea un clima de paz, aun cuando producto del proceso de conciliación no se hubiera llegado a un acuerdo, sí se ha logrado un entendimiento entre las partes, restaurándose la comunicación entre ambas.

\subsection{Economía}

$\mathrm{Al}$ adoptarse un acuerdo con rapidez los costos de proceso son bajos, debiéndose pagar tanto al conciliador como los honorarios del centro de conciliación. El proceso judicial y arbitral son más caros. 


\subsection{Rapidez}

La conciliación es un proceso rápido que puede concluir en una o varias sesiones, frente a otros procesos como el arbitral que suele demorar no menos de seis meses y el proceso judicial es, normalmente, mayor a seis meses.

\subsection{Protagonismo de las partes}

Las partes son protagonistas de sus decisiones. Las partes controlan el proceso, así como el resultado que es producto exclusivo de sus decisiones. A diferencia de lo que ocurre con el proceso judicial y el arbitraje, la solución no es delegada a un tercero sino que es retenida por los propios interesados. Las posibilidades de solución dependen de las partes.

\subsection{Flexibilidad}

En la conciliación se utiliza un lenguaje sencillo y directo, a diferencia de lo que ocurre en los procesos judiciales. En muchos casos es preferible recuperar las relaciones que mantener las formas, lográndose una solución de mayor permanencia, dado que se sustenta en los intereses y no en las posiciones.

\subsection{Informalidad}

En la conciliación no existe ningún tipo de requisito formal dado que cada parte participa voluntariamente y el conciliador hace uso de técnicas y herramientas que refuerzan la comunicación entre las partes.

\subsection{Solución realizable}

Por tratarse de una solución adoptada por las partes, en la conciliación las decisiones adoptadas logran un 95\% de eficacia. Es decir, son pocos los casos en los que las partes no cumplen con los acuerdos que ellos mismos han adoptado. Se trata de soluciones propias, producto de la creatividad de las partes, más que de soluciones formales que se adoptan por imposición de un tercero y que se sustentan en la ley y en la jurisprudencia. No se trata de encontrar quién tiene la razón sino más bien buscar entre las partes, utilizando su disponibilidad e inteligencia, las fórmulas más apropiadas al caso materia del conflicto. 


\section{Diferencias entre la Conciliación y el Proceso Judicial}

De acuerdo a las características y ventajas de la conciliación frente al proceso judicial, podemos concluir lo siguiente:

- Si tomamos en cuenta el tipo de solución al cual llegan las partes, podemos decir, que mientras en la conciliación la solución se da de acuerdo a los intereses de las partes, en el proceso judicial se da de acuerdo a sus posiciones.

- En cuanto al tiempo que demanda cada uno de dichos procesos, podemos señalar, que mientras un proceso de conciliación tiene una duración máxima de treinta días, el proceso judicial suele tener una duración mínima de tres meses.

- En lo referente al control del proceso, podemos señalar que en la conciliación, el control del proceso lo tienen las partes y en el proceso judicial dicho control lo tiene el juez.

- En cuanto al tipo de solución a las cuales llegan las partes, podemos señalar que mientras en la conciliación la solución la dan las mismas partes, siendo éstas voluntarias y creativas, en el proceso judicial las soluciones son de tipo coactiva y legal.

- Por último, quisiera mencionar y resaltar el grado de cumplimiento que se le da a los acuerdos, lo cual está estrechamente relacionado con las consideraciones antes mencionadas, trayendo como consecuencia que, mientras en la Conciliación ésta es de un alto grado, en el proceso judicial, es de un grado relativo.

\section{Estilos de Conciliación}

La forma de intervención del conciliador está destinada a facilitar a las partes que solucionen el conflicto. Sin embargo los conciliadores pueden adoptar diferentes estilos a fin de lograr cumplir su papel. Los estilos más conocidos según los autores Susan S. Silbey y Sally E. Merry son los denominados estilo negociador y estilo terapéutico, que para Leonard Riskin adoptan el nombre de estilo facilitativo y estilo evaluativo. 


\subsection{Estilo negociador}

Este estilo supone la presencia de un conciliador cuya meta es llegar a un acuerdo. Por tanto, el procedimiento debe permitirle el control del proceso y utilizar las herramientas más adecuadas con tal objeto. Tal es el caso de las sesiones privadas.

Para este estilo, el conciliador debe procurar llegar lo más pronto posible a una solución, controlando las emociones y señalando los beneficios del acuerdo. Por ello se considera un estilo pragmático donde las partes deben sentir las ventajas de llegar a un acuerdo.

Este estilo se puede asimilar al que Riskin denomina estilo evaluativo, donde el conciliador asume un rol activo tanto respecto del proceso como del fondo del asunto, haciendo pesar su experiencia y su conocimiento casi al límite de ejercer influencia sobre las decisiones de las partes.

Es la fórmula que Folberg y Taylor llaman «mediación legal».

\subsection{Estilo terapéutico}

La meta de la conciliación en este caso es ayudar a que las partes se sientan escuchadas, compartiendo sus emociones y sentimientos. Las emociones se tratan directamente usando incluso intervenciones terapéuticas. El conciliador no discute acerca de normas legales, sino más bien de alternativas sugeridas por las propias partes, sustentadas en la comprensión y en la recuperación de las relaciones, dado que se supone que la fuente del conflicto es un malentendido o una falla en la comunicación. El conciliador simplemente facilita la conciliación, esperando la solución del conflicto como una consecuencia natural. 